\title{
SOME GENERALIZED GRONWALL-BELLMAN TYPE DIFFERENCE INEQUALITIES AND APPLICATIONS
}

\begin{abstract}
ZIZUN LI
Abstract. We establish some generalized sums-difference inequalities involving a finite sum, which includes three sums and seven sums, respectively. We present the estimation of the inequality is decided by a finite recursion. Using the lemma and difference techniques, we transform the complex difference inequalities into the simple forms of difference inequalities. We apply our results to boundary value problem of a partial difference equation for uniform boundedness, uniqueness and continuous dependence of the solutions.
\end{abstract}

Mathematics subject classification (2010): 34B15, 26D15, 26D10.

Keywords and phrases: Difference inequality, monotonicity, boundary value problem, asymptoticity, boundedness.

\section{REFERENCES}

[1] A. Abdeldaim And A. A. El-Deeb, On generalized of certain retarded nonlinear integral inequalities and its applications in retarded integrodifferential equations, Applied Mathematics and Computation, 256, 375-380 (2015).

[2] A. Abdeldaim, A. A. El-Deeb, And Reda Gamal Ahmed, On retarded nonlinear integral inequalities of Gronwall and applications, Journal of Mathematical Inequalities, Volume 13, Number 4 (2019), 1023-1038.

[3] R. P. Agarwal, Difference equations and inequalities, Marcel Dekker, New York, 1992.

[4] P. Y. H. PANG, R. P. AgARWAL, On an integral inequality and its discrete analogue, J. Math. Anal. Appl. 194 (1995) 569-577.

[5] R. P. AgArwal, S. F. Deng, W. N. ZhAnG, Generalization of a retarded Gronwall-like inequality and its applications, Appl. Math. Comput. 165 (2005) 599-612.

[6] R. P. Agarwal, Y. H. Kim, S. K. Sen, New retarded integral inequalities with applications, J. Inequ. Appl. 2008 (2008) 15 pages.

[7] R. Bellman, The stability of solutions of linear differential equations, Duke Math. J. 10 (1943) 643-647.

[8] D. Bainov, P. Simeonov, Integral Inequalities and Applications, Kluwer Academic, Dordrecht, 1992.

[9] I. A. BIHARI, A generalization of a lemma of Bellman and its application to uniqueness problem of differential equation, Acta Math. Acad. Sci. Hung. 7 (1956) 81-94.

[10] C. J. Chen, W. S. Cheung AND D. ZHAO, Gronwall-Bellman-Type integral inequalities and applications to BVPs, J. Inequ. Appl. 2009 (2009) Art. ID 25856915 pages.

[11] W. S. Cheung, Some discrete nonlinear inequalities and applications to bounadry value problems for difference equations, J. Differ. Equat. Appl. 10 (2004) 213-223.

[12] W. S. Cheung, Some new nonlinear inequalities and applications to boundary value problems, Nonlinear Anal. 64 (2006) 2112-2128.

[13] W. S. Cheung, Some retarded Gronwall-Bellman-Ou-Iang-type inequalities and applications to initial boundary value problems, preprint.

[14] W. S. Cheung, J. Ren, Discrete non-linear inequalities and applications to boundary value problems, J. Math. Anal. Appl. 319 (2006) 708-724. 
[15] W. S. Cheung, Q. H. MA, J. Pecaric, Some discrete nonlinear inequalities and applications to difference equations, Acta Math. Sci. 28 (2) (2008) 417-430.

[16] S. K. ChoI, S. F. Deng, N. J. Koo AND W. N. Zhang, Nonlinear Integral Inequalities of BihariType without Class H, Math. Inequ. Appl. 8 (2005) 643-654.

[17] S. S. DRAGomiR, Y. H. Kim, Some integral inequalities for functions of two variables, Electr. J. Diff. Eqns. 2003 (2003) No. 10 1-13.

[18] A. A. EL-DEEB, On some generalizations of nonlinear dynamic inequalities on time scales and their applications, Applicable Analysis and Discrete Mathematics. 13 (2019), 440-462.

[19] A. A. El-Deeb, Haiyong Xu, A. Abdeldaim, And Guotao Wang, Some dynamic inequalities on time scales and their applications, Advances in Difference Equations, (2019) 130 (2019), https://doi.org/10.1186/s13662-019-2023-6.

[20] Q. H. Feng, F. W. Meng, B.S. Fu, Some new generalized Volterra-Fredholm type finite difference inequalities involving four iterated sums, Appl. Math. Comput. 219 (2013) 8247-8258.

[21] T. H. GRONWALL, Note on the derivatives with respect to a parameter of the solutions of a system of differential equations, Ann. of Math. 20 (1919) 292-296.

[22] Y. H. Kim, Gronwall, Bellman and Pachpatte type integral inequalities with applications, Nonlinear Anal. 71 (2009) 2641-2656.

[23] O. Lipovan, Integral inequalities for retarded Volterra equations, J. Math. Anal. Appl. 322 (2006) 349-358.

[24] Z. Z. LI, A generalized nonlinear sums-difference inequality and its applications, J. Math. Inequ. 12 (2018) 77-94.

[25] T. LV, Y. HuAng, A generalization of discrete Gronwall inequality and its application to weakly singular Volterra integral equation of the second kind, J. Math. Anal. Appl. 282 (2003) 56-62.

[26] Q. H. MA, E. H. YANG, Some new Gronwall-Bellman-Bihari type integral inequalities with delay, Periodica Mathematica Hungarica. 44 (2002) 225-238.

[27] Q. H. MA, W. S. Cheung, Some new nonlinear difference inequalities and their applications, J. Comput. Appl. Math. 202 (2007) 339-351.

[28] Q. H. MA, Some new nonlinear Volterre-Fredholm type discrete inequalities and their applications, J. Comput. Appl. Math. 216 (2008) 451-466.

[29] Q. H. MA, Estimates on some power nonlinear Volterra-Fredholm type discrete inequalities and their applications, J. Comput. Appl. Math. 233 (2010) 2170-2180.

[30] F. W. Meng, W. N. LI, On some new nonlinear discrete inequalities and their applications, J. Comput. Appl. Math. 158 (2003) 407-417.

[31] F. W. Meng, D. H. Ji, On some new nonlinear discrete inequalities and their applications, J. Comput. Appl. Math. 208 (2007) 425-433.

[32] B. G. PACHPATTE, On some new inequalities related to certain inequalities in the theory of differential equations, J. Math. Anal. Appl. 189 (1995) 128-144.

[33] B. G. PAChPatte, Inequalities for Differential and Integral Equations, Academic Press, New York, 1998.

[34] B. G. PAChPATte, On some new inequalities related to a certain inequality arising in the theory of differential equations, J. Math. Anal. Appl. 251 (2000) 736-751.

[35] B. G. PAChPATte, Integral and finite difference inequalities and applications, vol. 205 of NorthHolland Mathematics Studies, Elsevier Science B. V., Amsterdam, the Netherlands, 2006.

[36] H. Y. Qin, X. Zuo, J. W. Liu, Some New Generalized Retarded Gronwall-Like Inequalities and Their Applications in Nonlinear Systems, J. Contr. Sci. Engr. 2016 (2016) Art. ID 9527680, 8 pages.

[37] SH. Salem, Note on some systems of two discrete inequalities of Gronwall type, J. Math. Anal. Appl. 208 (1997) 553-566.

[38] W. H. ShenG, W. N. LI, Bounds on certain nonlinear discrete inequalities, J. Math. Inequ. 2 (2) (2008) 279-286.

[39] Yazhou Tian, A. A. El-Deeb, and Fanwei Meng, Some nonlinear delay Volterra-Fredholm type dynamic integral inequalities on time scales, Discrete Dynamics in Nature and Society, Volume 2018, Article ID 5841985, 8 pages.

[40] W. S. WANG, A generalized sum-difference inequality and applications to partial Difference equations, Adv. Difference Equ. 2008 (2008) 12 pages.

[41] W. S. WANG, X. L. ZHOU, An extension to nonlinear sum-difference inequality and applications, Adv. Difference Equ. 2009 (2009) 17 pages. 
[42] W. S. WANG, Z. Z. LI, Y. LI, Y. HUANG, Nonlinear retarded integral inequalities with two variables and applications, J. Inequ. Appl. 2010 (2010) 21 pages.

[43] W. S. WANG, Z. Z. LI, W. S. Cheung, Some new nonlinear retarded sum-difference inequalities with applications, Adv. Difference Equ. 2011 (2011) 11 pages.

[44] D. Willett, J. S. W. WONG, On the discrete analogues of some generalizations of Gronwall's inequality, Monatsh. Math. 69 (1965) 362-367.

[45] Y. Wu, X. P. Li, S. F. DENG, Nonlinear delay discrete inequalities and their applications to Volterra type difference equations, Adv. Difference Equ. 2010 (2010) 14 page.

[46] E. H. YAnG, On some new discrete Generalizations of Gronwall's inequality, J. Math. Anal. Appl. 129 (1988) 505-516.

[47] W. Zhang, S. Deng, Projected Gronwall-Bellman's inequality for integrable functions, Math. Comput. Modelling. 34 (2001) 394-402.

[48] B. ZHENG, B. Fu, Some Volterra-Fredholm type nonlinear discrete inequalities involving four iterated infinite sums, Adv. Difference. Equ. 2012 (2012) 18 pages.

[49] K. L. ZHeng, Y. Wu, S. M. ZHong, Discrete nonlinear intrgral inequalities in two variables and their applications, Appl. Math. Comput. 207 (2009) 140-147.

[50] L. F. ZHOU, W. N. ZHANG, A projected discrete Gronwall's inequality with sub-exponential growth, J. Difference Equ. Appl. 16 (8) 2010 931-943.

[51] J. ZHOU, J. SHEN, W. N. ZHANG, A powered Gronwall-type inequality and applications to stochastic differential equations, Discr. Conti. Dyna. Syst. 36 (12) (2016) 7207-7234. 